\title{
Research on the Pushover Methodology and the Applications on the Bridge Seismic Performance Improvement Scenarios
}

\author{
Wang Feng \\ The Engineering and Technical College of Chendu University of Technology; \\ Leshan City Sichuan Province,614000, China
}

\begin{abstract}
In this paper, we conduct research on the pushover methodology and the applications on the bridge seismic performance improvement scenarios. Bridge is an important part of the traffic lifeline engineering, and after the earthquake, if the bridge damage, that will hinder the timely disaster relief operations, increase secondary disasters, not only cause the direct or indirect losses of people's life and property, also affect the post-disaster recovery and reconstruction. Therefore, seismic design of the bridges has been people's attention. From the earthquake when the bridge failure mechanism and the failure process point of view, to adjust the overall layout design of bridge structure, fundamentally improve the structural seismic performance as a whole. Our research proposes the novel paradigm for the corresponding challenges that will be meaningful.
\end{abstract}

Keywords-Pushover, Applications, Bridge Seismic, Performance Improvement, Basic Scenario.

\section{Introduction}

Stability is a branch of mechanics that is frequently encountered problems in bridge engineering, and just as important as strength problem. With the increase of bridge spans and bridge piers of box girder thin wall and high, and the application of high strength material, the structure of global and local stiffness decreased, the stability problem is more important than ever before, and the intensity of the stability problem and the problem is different, as its function and structure required to find out the internal resistance, the imbalance between the deformation state of began to increase sharply, so it is a deformation problem, rather than the questions is a stress and strength, its main goal is to prevent imbalance steady state. Despite the curve bridge spans are generally small, and the overall stability generally can meet the design requirements, but for the sake of the convenience in the design of the overall stability of the structure necessary to consider the factors which influence, in the practical engineering for the factors affecting the stability of curved bridge is analyzed [1-3]. 


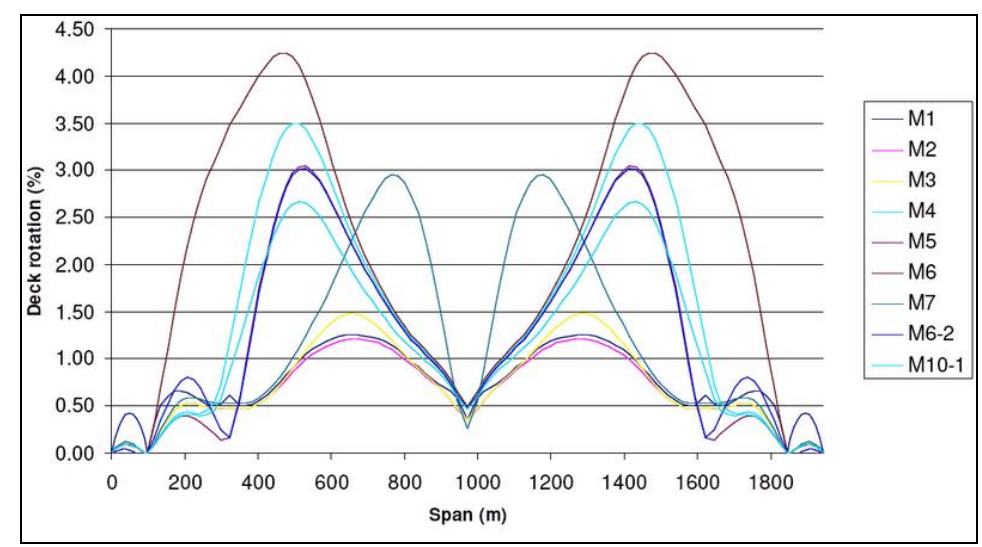

Figure 1. The Statistical Features of the General Bridge Seismic Performance

In the bridge reinforcement and reconstruction, should be based on the need to reinforce the bridge itself, than choose carefully for the factory case, full consideration of the various factors, reasonable choice according to the actual situation and economic benefit. Accordingly, the countermeasures can be summarized as the follows. (1) Expanding method of foundation reinforcement. Based hollowed or damage to the local situation, as well as the shallow embedded depth of foundation and so on, can be to expand the foundation base area, the basic unit pressure decreases to the foundation soil can allow under pressure range, i.e. to calculating the strength of soil base to determine the expansion to improve the bearing capacity of the pile foundation base area. (2) Broaden the way. Use of bridge foundation, depend on the pier, cover reinforcement, pouring out of the cantilever widened section, in order to make upper structure with cantilever installation widened section width. Using this method, the premise is the original pier foundation must be in good condition, stability, and experience meets the requirements of bearing capacity. (3) Add pile reinforcement method. Manner as the original pile foundation forms. In principle can be filling pile in the upstream and downstream position, can also be used in the original pile vertical direction along the bridge on both sides of the pile, and then expand caps base or capping beam that can make the old and new pile stress together [4-5].

In this paper, we conduct research on the pushover methodology and the applications on the bridge seismic performance improvement scenarios. Bridge upper structure is the main part of the bridge, and includes the construction process, construction technology and presents the characteristics of the diversification, the upper structure of the bridge construction can not only ensure the bridge using efficiency into full play as also directly affects the aesthetics and safety of the bridge is an important link in bridge engineering. In the later sections, we will analyze the issues in detail.

\section{The Proposed Methodology}

The Stability Features of the Bridge. The stability of bridge structure is related to the safety of the bridge structure, it has the same with the strength of the bridge is even more important. Once had a lot of bridges in the world caused by instability of the whole bridge damage example. With construction of high-grade highway, the application of the high pier Bridges will be more and more, the stability of the high pier mountain has become a bridge design must be considered an important controlling factor. It is well known that the lower part of bridge structure is connected with the upper structure, as a result of the existence of bearing friction resistance, have certain flexibility as a superstructure to the 
deformation of the shafts of the constraints, the existing theoretical formula normally only consider pier upper for freedom or hinged two situations, not considering the elastic about function, this makes the application of traditional formula has been limited.

According to the literature survey, the causes of the unstability can be reflected from listed aspects. (1) Never balance branch, the emergence of a new, have qualitative difference between the balances of form, the whole process is the balance of the original form number changes, at the same time, the deformation and stress state is no qualitative change. (2) Loss of the second category of the stable structure, lose bearing capacity, at this point, when the load reaches the critical value, even if you don't continue to increase the load, even reducing load, deformation and themselves will also increase.

Bridge structure is the essence of the general ultimate bearing capacity is extreme value point determination, the second category of stability for extreme value point problem usually adopt finite element theoretical analysis, by solving for the geometrical nonlinearity and material nonlinearity on the influence of the structural stiffness matrix, according to the equilibrium equation, the process of looking for the ultimate load, the structure under the effect of increasing external load, structural stiffness change constantly, when the load of compressive stress or shear stress makes the structure stiffness matrix tend to be singular, structural bearing capacity to reach the limit, at this time of the loading is the ultimate load of the structure. Additionally, we should take the listed conditions into the consideration. (1) If in the whole process of nonlinear analysis, take into every load increment as big, it will be not good. Because in the beginning, relatively small nonlinear structure, basic present linear structure, load increment can take a few bigger, in order to save computation time, when the load increases gradually, the contribution of initial stress stiffness matrix is more and more big, the tangent stiffness matrix determinant value drops rapidly, element stiffness is falling rapidly, load-deformation curve gradually flatten out. (2) Load incremental method is used to load stability analysis can only calculate the load-displacement curve of general rising period, when the incremental algorithms of to extreme value point and load-displacement curve of the slope to the zero, the tangent stiffness matrix singularity, stiffness matrix determinant is zero, no matter how small the load increment, the structure also cannot bear more load increment, and the displacement is increasing [6].

The Pushover Methodology. In recent years, seismic design method based on performance has become one of hot topics in the study of all countries in the world of civil engineering. Although the scholars for many years of research, the real practical application only Pushover method. 


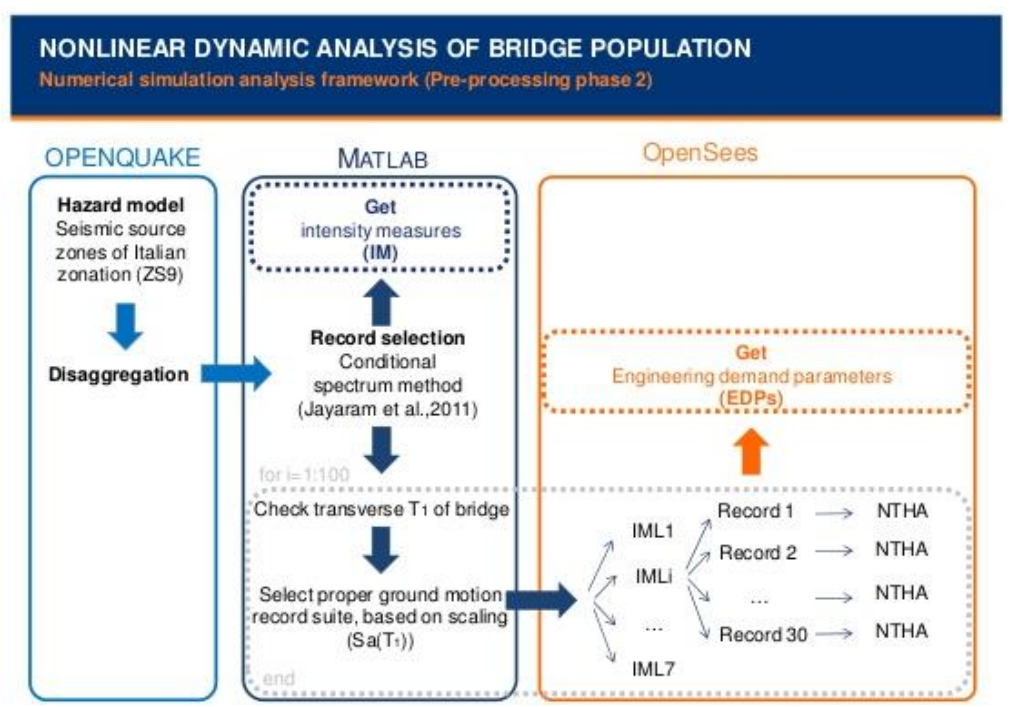

Figure 2. The Systematic Description of the Sample Pushover Methodology

Pushover method is according to the basic structure characteristics of the housing on the housing applying some distribution of horizontal force, and gradually increase along with the load increasing as part of components into the elastic-plastic stage, structural stiffness change thus gradually adjust the distribution of the horizontal force, this constantly, until the structure reaches a certain limit state. Using the elastoplastic seismic response of this kind of method to calculate structure will gradually accepted by the general engineering design personnel, but at present, for the use of static method to predict the dynamic responses of the structure, how its reliability has been attention by many scholars, but also for the existing strengths and weaknesses of did not give a comprehensive evaluation.

Earthquakes in the capacity spectrum method, in order to be the demand curve and the structural capacity curve superposition in the same coordinate system, we need to do some work simplification. Because of the demand curve is derived by the elastic response spectrum, it is in view of the single degree of freedom linear system, so the structure of the power curve should be also corresponds to the linear system of single degree of freedom. Displacement coefficient method is to use the pushover analysis and correction of the biggest displacement approximation method to determine the structure. Displacement is recommended for the influence coefficient method to determine the structure of the nonlinear maximum expected top displacement, the maximum expected displacement is defined as the target displacement and top floor displacement could be calculated as follows [7].

$$
X_{t, \max }=\mu X_{t, y}
$$

The ductility coefficient of equivalent single degree of general freedom system for $\mu$ that can take advantage of the strength reduction factor and ductility coefficient to calculate the ductility coefficient of single degree of freedom system, strength reduction factor is defined as follows.

$$
R_{\mu}=\left[F_{e, e q}\right] /\left[F_{\mathrm{y}, e q}\right]
$$

Accordingly, we suggest the corresponding relational expression as follows.

$$
\begin{gathered}
R_{\mu}=(\mu-1) \frac{T}{T_{0}}+1 \\
R_{\mu}=\mu \\
T_{0}=\text { Cons } \times \mu^{0.3}
\end{gathered}
$$


Its structure can be converted to the formula of equivalent single degree of freedom system is not the only, but the equivalent principle of the roughly the same. That all the dynamic equation of the equivalent through the multi degree of freedom system as multilayer structure can often be ideal into multi degree of freedom system in each floor has a concentrated mass. Displacement coefficient method of calculation steps are as follows. (1) The structure of the calculation model is set up, that restoring force curve of each unit. (2) Choose a lateral load distribution patterns, the structural static elastoplastic analysis, get the top of the structure relationship of base shear displacement curve into two line form that determine the top yield displacement. (3) It will be equivalent to a single degree of freedom structure system, the calculation of the ductility coefficient of equivalent single degree.

The Anti-seismic Bridges. Anti-seismic concept design refers to according to the earthquake disaster and the engineering experience of the basic design principles and design ideas, properly solve structure overall scheme, material use and the detail structure, in order to achieve the purpose of the reasonable seismic design. Reasonable seismic design requirements designed structure on the indexes such as strength stiffness and ductility are the best combination as the structure is able to achieve the goal of seismic fortification economy.

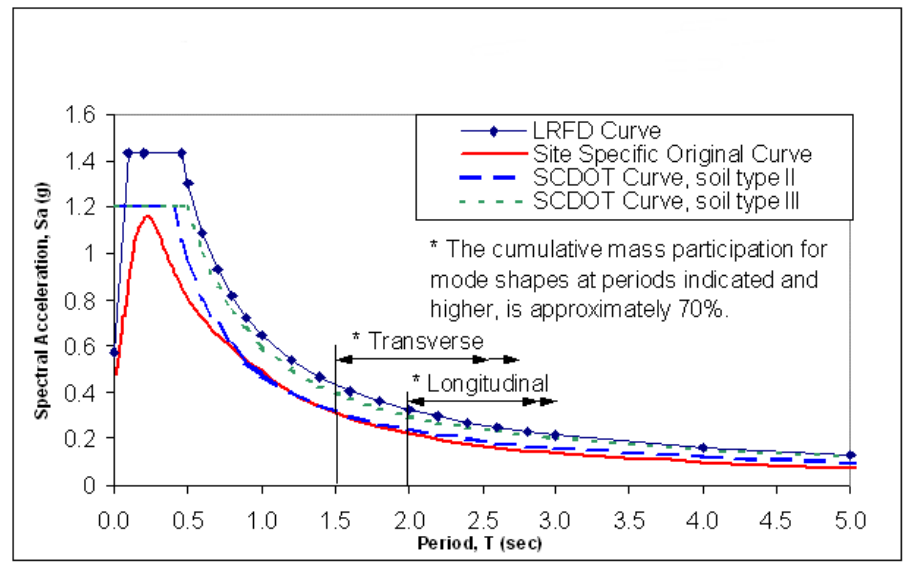

Figure 3. The Seismic Performance Improvement Simulation and Verification

Seismic strengthening of main purpose is to prevent the bridge collapsed across, the second is to damage, damage control to a certain degree. In seismic design of bridges, gravity and use under the load of the upper structure is designed according to the elastic, they usually are designed to be a strong link in seismic system. During the earthquake basically keep elasticity, bridge upper structure beam collapse and the impact damage that is caused by ground motion shaking of the bottom structure and different pier column, or caused by the adjacent bridge expansion joint impact each other. Therefore, for bridge structures, seismic strengthening, the emphasis was on the bottom of the bridge structure. Based on the prior discussed countermeasures, we propose the following suggestions.

- The reasonable application of the pendulum sliding friction bearings. Bridge structure design personnel in the process of general bridge structure design must fully consider the effective application of the tilting sliding friction bearings how to improve the seismic safety of the structure of the bridge [8].

- The reasonable application of viscous dampers. In the process of the bridge structure design personnel in the general 
design of bridge structure should fully consider the how to effective application of the viscous dampers improves the seismic safety of the structure of the bridge. Viscous damping apparatus has its unique advantages, first of all, elastic-plastic damping device or friction damping device yield or friction is constant, the maximum deformation in the bridge pier, the yield strength or friction constant will reach at the same time.

- In the process of the bridge structure design personnel in the design of bridge structure should fully take into account how to effectively lead core rubber support of application of improve the seismic safety of the structure of the bridge. Lead the structure of the rubber isolation bearing in hierarchical add lead rubber bearing, constitute a reduction of isolation.

\section{Conclusion}

In this paper, we conduct research on the pushover methodology and the applications on the bridge seismic performance improvement scenarios. Seismic response analysis of structural seismic design is the main work content and basis. The response of the structure under seismic action is a kind of random vibration, the vibration isolation design for the bridge, due to the reduced nonlinear vibration isolation device, under the design seismic force, even if the main structure is in elastic state, isolation, shock absorbing device, in general, should be entered into the phase of nonlinear energy dissipation effect can be used at this time based on the response spectrum method of equivalent linearization is analyzed. Therefore, our research combines the pushover methodology to propose the novel bridge seismic performance improvement scenario that is innovative.

\section{Reference}

[1] Johnson, Nathan S., Mark L. Creveling, and Keith J. Gazaway. "North Torrey Pines Bridge Seismic Retrofit: Part II, Structural Analysis and Design." Earthquake Spectra 31.4 (2015): 2211-2233.

[2] Su, Donglan, et al. "Rapid Diagnostic Model of Road Lifeline Seismic Damage Based on Seismic Intensity." Access Management Theories and Practices. ASCE, 2015.

[3] Tehrani, Payam, et al. "Effects of different record selection methods on the transverse seismic response of a bridge in south western British Columbia." Journal of Earthquake Engineering 18.4 (2014): 611-636.

[4] Fouché, Pierre, Michel Bruneau, and Vincent P. Chiarito. "Modified Steel-Jacketed Columns for Combined Blast and Seismic Retrofit of Existing Bridge Columns." Journal of Bridge Engineering (2016): 04016035.

[5] Zafeirakos, Athanasios, and Nikos Gerolymos. "Towards a seismic capacity design of caisson foundations supporting bridge piers." Soil Dynamics and Earthquake Engineering 67 (2014): 179-197.

[6] Du, X. T., Y. L. Xu, and H. Xia. "Dynamic interaction of bridge - train system under non uniform seismic ground motion." Earthquake Engineering \& Structural Dynamics 41.1 (2012): 139-157.

[7] Zhao, Zhi Meng, et al. "Research on Seismic Resistance Performance of Continuous Prestressed Concrete Girder Bridge at Strong Earthquake Zone." Applied Mechanics and Materials. Vol. 353. 2013.

[8] Chang, K. C., C. W. Kim, and Sudanna Borjigin. "Variability in bridge frequency induced by a parked vehicle." Proceedings of the 4th KKCNN Symposium on Civil Engineering. 2014. 